drops before I could produce an impression on the disease. I should observe that the tincture was not made with resin brought from India, but with that prepared by Mr. Squire from the dried plant. Before I saw the case under consideration, I had administered the hemp resin in a few cases, but the itchiness (if any existed) escaped my notice. Since I observed the itchiness in $\mathrm{B}-\mathrm{I}-\mathrm{r}$, I administered several large doses (120 drops or six grains in each) to a gentleman aged sixty-four, of very robust make, but not corpulent. He had recently been under my care for a urinary affection, from which he had recovered, and having heard of the gunjah, out of curiosity requested to have some. 120 drops of my tincture produced heat of the skin, considerable exhilaration, with itchiness at the roots of the eyelashes and in a few points of the lower extremities and scrotum. 'There was no sexual excitement; he felt drowsy after the expiration of three hours, but being amongst cheerful friends, easily resisted the inclination to slecp. In him the itchiness was so moderate that he only named it in reply to my question. This gentleman smoked daily half a dozen cigars at least. I think decided tobacco smokers bear a larger dose of the hemp than others. The hemp does not produce constipation.

7, Delahay-stredt West, March 24, 1843.

\section{CASE OF HYDROPHOBIA.}

TO THE EDITORS OF TIE PROVINCIAL MEDICAL JOURNAL.

Gentlemen, - Should the following case of hydrophobia be deemed of sufficient interest to merit a place in your Journal, I should feel obliged by its insertion.

I am, Gentlemen, Yours respectfully,

Liverpool Northern Hospital,

E. PARker, House Surgeoll. March 21, 1843.

James M'Lellan, aged forty, carpenter, of temperate habits, was admitted on Thursday, March 2, under Dr. Carson. He stated that on the night of the 23rd of September last, when crossing one of the canal bridges, he heard a splash in the water; he went down to the bank, and saw a dog struggling in the canal. In assisting the animal to get out, it snapped at and bit two of his fingers, which bled freely, and gave him considerable pain. He bathed them with some rum, and in the course of eight or nine days they were quite well. Has felt no inconvenience from the bites since they healed, and does not believe that his present illness has any connection with them. For some weeks past he has been troubled with a cough, and for the last three or four days suffered from what he describes as a cold. Returning from his work on Tuesday evening, he felt more than usually fatigued, and, during the night, his wife states that she observed a great alteration in his tempcr, which had become exceedingly irritable-that he got up several times and walked about the room. On Wednesday morning he went to his work as usual, but returned in a few hours, complaining of headache and sickness. Some coffee was given to him, which he threw up, and on taking some more, felt a strange sensation, "all frightened." The symptoms continued to increase; he became more and more agitated. Late in the evening a medical gentleman was sent for, who requested him to drink some water, the thought of which now inspired him with an ungovernable feeling of terror. On the following morning he was brought to the hospital. When first seen he started up, and prayed that we would not disturb him; he said that he had no pain anywhere, no uneasiness in the bitten fingers; tongue furred; pulse 100, rather feeble; bowels open; skin soft and moist; countenance anxious. Turning, unknown to him, one of the taps, as soon as the water began to flow he jumped up in a paroxysm of fcar, and begged it might be stopped; he could not help it, he said, but it was more than he could bear. When placed in bed, he was observed to spring up every now and then, to put his hands on his chest, and express a fear that he could not breathe. Any sudden movement of the bystanders, or even a current of air, served to bring on similar attacks. He says that if he attempted to drink any fluid, the paroxysms would be frightfully increased; even speaking to him of liquids caused an evident agitation. There is no stiffness in the muscles of the jaws, and no difficulty in swallowing solids. Five minims of prussic acid were ordered to be given every half hour; by dropping the acid on a piece of bread, it was administered without difficulty. At the end of four hours the attacks had become more frequent and more scvere; the slightest causes were sufficient to excite them. Opening the door of his ward, or arranging his bed-clothes, secmed to impress him with the greatest dread; he would spring up in a paroxysm of despair, throw his arms round the neck of his attendant, and implore, in the most piteous language, that he might not be so annoyed. In these attacks he evinced no inclination to injure himself or others, and apparently suffered no bodily pain. An intense, ungovernable, indescribable feeling of alarm, expresses most accurately his condition. For a short time his fears seemed to be excited by the supposed presence of some trifling object in a corner of his ward, but this illusion soon disappeared; his countenance at this time was strongly indicative of his feelings, and expressed the highest degree of terror.

During the intervals between the paroxysms, which recurred every three or four minutes, he was perfectly rational and collected, apologised for his unruly conduct, spoke with affecting carnestness of his family, and, in taking leave of his wife, and giving instructions respecting his domestic affairs, did so with a pathos scarcely to be expected from a man in his condition.

At five o'clock twenty drops* of the tincture of Indian hemp, containing one grain of the extract, were given, and repeated every hour. Three doses were taken, but it did not seem to produce any effect;

- The doses of hemp administered to inhabitants of this country should be much greater than those given to natives of India. No effect could be expected to follow from so small a dose as twenty drops. One of the Editors of this Journal took six grains of the extract, and smoked a scruple of the gunjah, with no other effect than the inducing a desire to slcep.-Eus. 
the fits recurred, increasing in fearful intensity, to such a degree that to keep him in bed, or even in the ward, recourse was obliged to be had to restraint. He seemed quite aware of our intention in so doing, and hoped we should prevent him from injuring himself; but during the attacks, now almost constantly present, he was perfectly furious, and made violent efforts to free himself, crying out lustily, and spitting constantly a frothy mucus, tinged with blood. Even now at intervals he was conscious, and recognised me on speaking to him. The effects of his powerful exertions, and of the copious perspirations, now began to be cvident; the pulse increased in quickness, and became more feeble. For a short time before his death, which took place between seven and eight o'clock, he lay quict on his back, quite exhausted, breathing with difficulty, dilated pupil, and with considerable accumulation in the air passages.

Inspection, Eighteen Hours after Death.

The body having been placed on its face, to prevent any deceptive appearances from position, the brain and spinal cord were carefully examined, but no trace of disease could be observed in either. There was no preternatural redness of the mucous membrane of the pharynx; the lungs were of a dark purple color, and much congested; extensive adhesions on the right side; the mucous membrane of the trachea and bronchia greatly injected, the latter of a purplish color; the tubes were loaded with frothy, tenacious, bloody mucus, similar to what he had spat up during life; the heart presented no unhealthy appearance; the stomach contained a quantity of greenish fluid; the gall bladder was much distended. During the examination it was observed that the blood which flowed seemed to be somewhat thinner than natural.

Though, in the present state of our knowledge, the publication of the above case may not be useful, as illustrating any principle in treatment, or any point in pathology, I yet think it right to place it on record -first, because an accumulation of such may at some future period, when more is known of the many obscure questions its consideration involves, afford materials from which, by comparison and induction, some elucidation of its nature may be obtained; and, secondly, its mere perusal may lead those who meet with cases of bites to a careful investigation of the condition of the animal, and, if necessary, to the adoption of those measures which alone can prevent the accession of the disease. Though, far from stating that prophylactic measures are always necessary, I cannot but think that we are too apt to neglect inquries, which, in some cases at least, would supply information of the utmost importance. How frequently does it happen, when applied to by patients who have received a bite, that the wound is dressed without any investigation into the state of health of the animal that inflicted the wound; or, if any injury is made, are we not generally satisfied with the remark that the dog "seemcd well ?" In such cases, and most particularly in those which have been received without any provocation, should not our examination extend further? Ought we not, in fact, in every case of bite, to insist on the propricty of securing and watching the dog for a few days? If symptoms of rabies are manifested, we may then have recourse to treatment which, without such certain information, would most probably not be proposed by the surgeon, or not submitted to by the patient.

M'Lellan was frequently asked by his fellowworkmen if the dog was mad, but considered all such inquiries as trifling with his feelings. Had he taken the alarm, and ascertained its fate, there can be little doubt but he could have been saved from falling a sacrifice to the fearful disease which so quickly put a period to his life.

\section{PROVINCIAL MEDICAL JOURNAL}

\section{SATURDAY, APRIL 1, 1813.}

The observations which we addressed, in the last two numbers of this Journal, to the members of the medical profession, on the present aspect of medical reform, have been responded to by the practitioners of Surrey in a becoming manner.

We were of opinion that the time for action, on the part of the general practitioners of the United Kingdom, had arrived; and this opinion has received the highest sanction from the leading members of the Provincial Association, and from all those who have hitherto stood forward as able and earnest advocates of the interests and dignity of the medical profession.

The following account of the meeting of the Surrey practitioners, held at Epsom on the 24th of March, will serve at once as an example and a stimulus to their brethren in all parts of the kingdom. Nothing can be more moderate than the prayer of the Surrey petition; it simply requests " that the legislature cause inquiry to be made into the present state of the medical profession, and more especially into that of the general practitioners; delaying any legislative measure which might lead to the granting of new charters to the Colleges of Physicians and Surgeons, until the whole subject of medical regulation and reform has been well and thoroughly investigated by a committee of the House of Commons, and has undergone adequate discussion in Parliament."

We believe that so temperate and just a demand will obtain universal support; and we earnestly hope that measures will be forthwith taken, in the different towns throughout England, to obtain petitions of a similar nature to both Houses of Parliament. The members of the Provincial Medical and Surgical Association will not, we feel assured, be wanting in zeal or prudence at this crisis of medical affairs.

The number of towns in the United Kingdom, in which members of the Provincial Association reside, amounts to several hundrcds; and from all, or from a majority of these, petitions might be forwarded. We believe that a succession of petitions addressed to both Houses, from the various towns 